\title{
The normative implications of the longevity transition
}

Kenneth Howse

Senior Research Fellow

Oxford Institute of Population Ageing

University of Oxford

66 Banbury Rd

Oxford OX2 6PR

kenneth.howse@ageing.ox.ac.uk

\begin{abstract}
This paper explores some of the normative implications of changes in the age profile of longevity improvements. The discussion assumes that in many ageing societies there is still a sense of collective ambivalence about the benefits conferred by continuing longevity increases. Different approaches are considered to making a collective reckoning of the benefits conferred by continuing longevity gains when the age profile of these gains is undergoing profound change. The requirement to make such reckonings raises novel normative problems for policy.
\end{abstract}




\section{A longevity revolution?}

There has been a remarkable transition in human longevity since the middle of the last century. Although life expectancy at birth increased throughout the twentieth century in high income countries, for several decades these gains were driven mainly by reductions in early life mortality. This changed in the second half of the century. The mortality reductions that were powering the continuing improvement in life expectancy at birth shifted to progressively older ages. Not only were more and more people surviving to pensionable age, but they were surviving for longer in old age. By the end of the century, it was clear that previous assumptions about an imminent slowdown in longevity gains (as they depended increasingly on improving survival for people in their 80s and 90s) had to be discarded; and for the time being at least, there seems little reason to reverse this judgement. In most low mortality countries, the modal age at death continues to increase (Canudas-Romo 2010, Horuichi et al 2013).

This longevity transition has been accompanied in most of the world's richer countries by a fall in fertility rates to levels that are sufficient to put a brake on population growth. When fertility is just below replacement level, the brake is applied quite gently (as in the USA). There are, however, many countries in which the brake on population growth is being applied sharply enough (persistent low fertility) for a realistic planning horizon to include a likely transition from population growth to population decline. The combined effect of the brake on population growth and the longevity transition shows up in a shift in the age structure of populations - from 'youthful' to 'mature' - that is generally taken to represent a permanent reconfiguration of the demographic landscape, and it is often measured by looking at changes in dependency ratios. 
Although the practical and policy implications of large-scale age structural change in the population overlap with those that result from continuing longevity gains, they are not identical (Eggleston \& Fuchs 2012). The fundamental challenge that results from continuing longevity gains can be conceptualised in terms of changes in patterns of risk and opportunity faced by individuals across the typical life course. Longer lives have implications for the way we manage, and prepare for, various critical transitions - such as the transition from work to retirement, or from health to ill-health and disability - and these define the challenges both for individuals and for society. A great deal of policy effort is aimed not only at delaying these transitions (i.e. recalibrating institutional arrangements, such as the timing of retirement, in line with an extended lifespan), but also at enhancing the various resources that individuals draw on to deal with them. Broadly, speaking, we know what we are trying to do: delay unwelcome transitions where possible (maintain health, activity and productivity for longer); enable individuals to take better advantage of the opportunities that result from increased longevity (poor health and low income are the most obvious barriers to the enjoyment of later life); improve protection against the shocks or losses that also result from increased longevity (which will include the risk of serious disability). How much of this 'prudent planning' falls to individuals and how much is managed by government varies between countries with different kinds of public welfare arrangements. Ageing societies will almost certainly combine policies that help individuals to protect themselves more effectively against changing patterns of risk with policies that offer improved provision of care or support in the face of shocks that cannot be avoided. It may prove very hard, moreover, to avoid policy decisions that reconfigure the respective responsibilities of individuals and households, on the one hand, and governments, on the other; and this raises issues that are often discussed in terms of fairness. 
We can distinguish challenges that are defined in terms of the allocation of resources across the typical life course from challenges that deal with the flow of resources between population groups defined by a position in the typical life course. A shift in the age structure of the population changes the relative size of different age groups, and for societies which make heavy use of general taxation or social insurance as a means of financing age-related benefits, this presents a major policy challenge because of the potential impact on the flow of public resources between groups at different stages of the life course. Age structural change, moreover, constrains and complicates policy responses to the longevity transition. The policy implications of population ageing - as an outcome which is the combined effect of the longevity transition and subreplacement fertility - have been the focus of an enormous amount of discussion and analysis. That there is, furthermore, an ethical or normative dimension to some of this debate is apparent in the importance attached to arguments about intergenerational justice, and what makes these arguments interesting is their novelty (Howse 2014). We are asked to consider different ways of extending or refining or revising our normative ideas about distributive justice in order to guide policy responses to a profound change in the circumstances of social life.

My aim in this paper is to consider whether and how such an extension or refinement of normative ideas might be required of us specifically as a result of the longevity transition, that is to say, apart from any issues that are generated by the wider phenomenon of population ageing. One evident consequence of the longevity transition is the continually increasing modal age at death, and uncertainty about the implications of this phenomenon for the quality of the transition from life to death has fuelled debate on the normative constraints that govern this transition (e.g. Daniels 2008; Fleck 2010; Gruenwald 2012). We have seen a shift in public opinion on these matters, in favour of 
a strengthening of the constraint against age-based rationing in healthcare (Oliver 2009), and a weakening of the constraint against assisted suicide. My concern here, however, is with neither of these issues (on which there is already a very large literature), but with another aspect of our normative thinking about the longevity transition. What I have in mind is uncertainty about whether or not we are better off, as a society, with continuing longevity gains, and I want to suggest that this is a question which does indeed require us to refine or extend our normative ideas. Most of the paper will be given over to examining the policy relevance of this judgement and the normative considerations that bear on it. As with arguments about intergenerational justice, what is interesting about this question is its novelty and its complex ramifications.

\section{The idea of premature mortality and the normative significance of the longevity transition}

My starting point is that the longevity transition takes us from a social condition in which life expectancy improvements are driven mostly by reductions in premature mortality to one in which the improvements come mostly (and increasingly) from reductions in 'non-premature' mortality. The reason for putting the matter in this way is that there is a standard view of the importance of premature deaths, which ascribes to them a kind of social cost (i.e. a cost that we collectively bear) that non-premature deaths lack. The losses or costs I have in mind are those that we can identity over and above the loss to the individual who dies (however we characterise this), or the loss that is constituted by the rupture of important affective ties. Households lose essential sources of income, dependent children lose parents to raise them, the community loses productive workers and may also incur the costs associated with the support of families and households who have lost their main source of income. Premature deaths occur at ages when we might 'reasonably expect' them to entail this kind of loss or cost (which 
is a present loss in the case of adults who die prematurely, and a future loss in the case of children). In other words, premature deaths are associated with a significant loss of human capital in a way that non-premature deaths are not.

If we adhere to this essentially qualitative distinction between premature and nonpremature mortality, the longevity transition has major implications for our understanding of how we benefit from continuing longevity increases. The transition will alter our reckoning of the gains from mortality decline, by which I mean the reckoning we make as a society rather the reckoning we make as individuals ${ }^{1}$. We move from a condition in which the 'social' benefits of mortality reduction are considerable and easy to identify - it is easy for us to see how we (collectively) are better off as a result of reductions in premature mortality - to a condition in which such benefits appear to be limited, even though the 'private' benefits (i.e. the benefits to individuals and their loved ones) may be clear. In effect, what happens is that as mortality gains start to shift to older ages, and the social benefits of continuing mortality reduction become increasingly problematic, the purely private benefits - the benefits to individuals and their immediate circle, some of which may be hard to monetize dominate our reckoning of what we gain from increased longevity.

Does any of this matter? If we are required to make some such reckoning in order to guide or justify our policy choices, then it matters that we are no longer sure how, or indeed, whether we are better off as a result of continuing longevity gains. It is at the very least disconcerting that the social benefits from longevity increases should be questionable when advanced democracies have socialised many of the costs associated with extended survival in later life, and when they find it difficult to rein in these costs so that they do not exert undue pressure on other desirable forms of public spending.

\footnotetext{
${ }^{1}$ i.e. whether $I$ think that $I$ am better off as a result of the changing mortality risks.
} 
Under these conditions, it is arguable that the dominance of purely private benefits in our reckoning of gains from continuing longevity increasingly undermines the legitimacy of certain kinds of welfare spending, especially those kinds of spending that directly contribute to continuing longevity gains. The rest of this paper will outline two different major criticisms of this account of the significance of the longevity transition, and some questions that arise out of them. Both the criticisms and the questions deal with the reckoning we make of the benefits of the longevity transition (or rather with the various considerations that are deemed relevant to the outcome of such a reckoning), as well as with the suggestion that there is something problematic about the dominance of purely private benefits in our reckoning of these gains.

\section{Reappraising social benefits}

The longevity transition, given the standard view, leads to declining social gains from continuing longevity increases. A familiar challenge to this assessment argues for policy reforms and changes in attitudes that will lead to a positive reappraisal of the social gains. The standard view connects age and the ability to be socially productive in an out-dated way, and it makes use of an excessively narrow interpretation of social productivity.

Improvements in health status at older ages have overturned what might previously have been reasonable expectations about the ability to remain socially productive. We are not just living longer, but we are living longer in better health. Because institutional arrangements have not caught up with these changes in individual ageing trajectories, ageing societies should be able to reap considerable social benefits from longevity gains. They are prevented from doing so by adherence to policies and institutions that stand in the way of adaptive change, and the result is a waste of human capital. Older 
people, moreover, can contribute to the welfare of families and to the wider community without having paid employment. In other words, we can change both institutions and ways of thinking (about what counts as socially valuable productivity) so as to alter the reckoning of the social benefits that come from longevity gains. What we have to do as a society is redesign institutions so as to enhance and harness the capacity of older people to contribute, and this does not square with institutional rigidity in the way we connect age and the ability to be socially productive. If we take this point about flexibility seriously, we should discard the idea of a fixed age boundary as a way of separating purely private benefits from social benefits (i.e. it is not enough simply to move the age boundary).

If there is anything problematic, therefore, in our reckoning of the social gains from continuing longevity increases, it can be resolved partly by implementing policies that allow us to realise the potential benefits, and partly by acknowledging and giving due weight to the value of the non-economic contribution made by older people to our shared social life. It is accepted that it would indeed be disconcerting if purely private benefits were allowed to dominate our reckoning of what we gain from continuing longevity increases, but this is an outcome we can avoid. Although we discard the distinction between premature and non-premature mortality as a way of separating purely private benefits from social benefits, we retain a sense of the importance of social productivity for the continuing legitimacy of a welfare contract between the generations.

In other words, the identification of non-negligible social benefits from continuing longevity increases is a matter of concern, and presumably this is because the reckoning matters for our sense that the 'moral economy' is in good order (Tepe \& Vanhuysse 
2009). We do not, however, go so far as to ask that the recalculated social benefits should fully offset the socialised costs, just as we do not demand that there should be no 'discrepancy' between capacity to contribute and actual contribution. In a liberal democracy which sets a high value on leisure and the opportunities it provides, such a demand would clearly be thought excessive. It is accepted that there should be no obligation on individuals to contribute up to the very limit of their capacity (e.g. continue working until they are unable to do so). What we expect rather is a fair contribution, and fairness in this case should leave time for the enjoyment of what we have come to think of modern retirement - an extended period of leisure taken at a time of life when capacity to be active is relatively intact. The obligation to be socially productive starts to weaken before people reach an age at which their capacity to be active significantly declines.

Since this first criticism of the standard view undermines the rationale for the distinction between premature and non-premature deaths, we should take note of the fact that the distinction is still widely used in discussions of government action to improve the health of their populations. On the standard view, the social benefits that result from the reduction of premature mortality give government a good reason to adopt such a goal as an explicit public health objective. We do indeed find that democratic governments tend to target premature mortality rather than overall mortality. Moreover, if the standard view is correct, we would also expect the justification for action on the reduction of premature mortality to change as it falls to ever lower levels. Developing countries with relatively high mortality are more likely to appeal to social benefits than developed countries with relatively low mortality, and for obvious reasons. Hence it is that as the potential social benefits diminish, considerations of fairness become increasingly important to the case for action. Indeed it seems (in public debate on this 
matter) that as premature mortality falls to increasingly low levels, the elimination of 'pockets of inequality' - parts of society with higher than average levels of premature mortality - takes on an ever higher priority. The disadvantage suffered by the minority becomes more glaring as more people find themselves in the majority.

What then are the implications of the criticism of the standard view for the significance of premature mortality for public health priorities? One option is to accept that we have no use for the distinction between premature and non-premature deaths in shaping policy. After all, why should we give special significance to inequalities in premature mortality? Social inequalities in mortality are unfair irrespective of the ages we might look at, and we should be no less concerned about the length of time spent 'in modern retirement' than about the chances of having any time in modern retirement. The problem is unfairness and the real opportunity with which we should be concerned is the opportunity for a long and healthy life. The other option is to recast the distinction between premature and non-premature deaths. We could appeal, as I have done in an earlier section, to the idea of modern retirement, or rather equality of opportunity in respect of 'access' to modern retirement. This would commit government to action to reduce inequalities in mortality and ill-health before this time of life is reached. Or we might reformulate the idea of premature mortality so as to make it independent of the capacity to be socially productive, and the most likely candidate for this role is some variant of the notion of a 'fair innings' that would peg premature mortality to average life expectancy. It should be pointed out that the notion of a fair innings is not being used here to curtail entitlements to certain kinds of health care that are otherwise generally available (Williams 1997), but rather to set public health priorities.

\section{The importance of private benefits and their distribution}


The argument in the previous section criticised the standard view on the grounds that the distinction between premature and non-premature mortality is not fit for purpose as a way of separating purely private benefits from social benefits. The second challenge to the standard view argues that there is nothing problematic in the dominance of purely private benefits in our reckoning of what we gain, as a society, from continuing longevity increases. Instead of holding on to the idea that the distinction between social benefits and purely private benefits matters for our assessment of the gains that ageing societies derive from longevity improvements, we reject it as unhelpful or irrelevant for policy. It does not matter if, as a result of the longevity transition, purely private benefits dominate our reckoning of the benefits of continuing longevity gains; and it is simply wrong to suppose that this dominance in any way undermines the legitimacy of public spending that contributes to or results from continuing longevity gains. The fact that we are better off as individuals is quite properly included in our collective reckoning (e.g. Murphy \& Topel 2006), and indeed the whole question about declining social benefits is a red herring. There is no reason why we should try to identify nonnegligible social benefits.

We can reformulate this point to make a forceful criticism of the assumption behind the standard view, which is that it misunderstands the rationale for socialising the costs of health care. Although it may indeed be strengthened by the achievement of social benefits over and above the private benefits secured to individuals, we should not lose sight of what is the most important line of reasoning in the case for socialisation, which is an appeal to social justice or solidarity or equity. It is true that we benefit as individuals by contributing to an insurance scheme which covers us for the payment of costs that we may not be able to afford if we should fall ill, but the case for including everyone in the risk pool - even if their lifetime contributions are low or negligible - 
relies on an appeal to social justice rather than efficiency, as well as an acknowledgement that we should attach a special status to the benefits that effective health care secures for individuals.

One very important consequence of the decision to highlight, in our collective reckoning of the benefits of continuing longevity gains, the value to individuals of what they themselves gain by having longer lives (i.e. the private benefits), is that we are bound to consider their diffusion through society (Marmot 2010; Mackenbach 2012). Once we accept that the case for socialising the costs of healthcare has been made, and rests moreover on an appeal to equity (i.e. not 'leaving people behind'), then we are forced to the conclusion that the population distribution of this extraordinary private good (the fact that some individuals gain more from the longevity transition than others) is a proper concern for government (Overall 2003). From this conclusion a great deal follows, not least that we have to take a view on what counts as a better (i.e. fairer) distribution.

\section{The dismal view}

Although the two criticisms of the standard view differ in the importance they attach to securing and/or identifying social benefits from continuing longevity increases, they share a positive view of the benefits these increases confer on individuals. Scepticism on this point may nowadays seem rather heterodox, but it is as well to bear in mind that it used to be quite commonplace in academic circles, and still persists in the media and public debate. From this perspective, the dominance of purely private benefits in our collective reckoning of the gains from increased longevity is problematic, mainly because it fails to take proper account of negative or unwanted outcomes. The problem 
lies with the increased risk of serious functional loss (and especially cognitive impairment) that comes with longer life spans.

To be clear about what is being claimed here, it is not in dispute that we gain a lot (as individuals) when the risk of premature mortality falls to levels which can be treated as insignificant for planning purposes, e.g. when it ceases to make much sense to take out life insurance for dependents, nor that we gain by improvements in healthy life expectancy that enhance our capacity to be active in retirement from paid employment. What is questionable is the 'net' benefit to individuals from continuing increases in life expectancy at older ages (e.g. 85 years) once the risk of premature mortality has become negligible. The dismal view argues that the effect of these increases will be (i.e. eventually) to normalise a species of extreme human misfortune that is currently beyond the reach of our capacities to provide help and assistance (Carnes \& Olshansky 2007). Because we are living for longer, we are also ageing for longer (Brown 2007). For an increasing proportion of the population, this extension of the ageing process will include a more or less prolonged period of physical frailty and cognitive impairment prior to death. By pushing death farther into advanced old age, we are increasing the risk that individuals will experience a condition characterised by loss of effective agency and loss of dignity, even perhaps loss of 'selfhood'. Since continuing mortality declines at older ages are exposing an increasing proportion of the population to a risk (to individual well-being) for which it cannot offer effective protection, our collective reckoning of the benefits from longevity gains must surely be revised to reflect this.

There is, for sure, a great deal of heterogeneity in the older population, and there will be some whose lives clearly demonstrate the possibility of successful ageing in its most desirable form - a long and active lifespan without cognitive impairment combined with a relatively short dying trajectory. But it is simply wrong (on the dismal view) to 
suppose that we know what to do in order to extend this form of successful ('win-win') ageing much more widely through the population. Although governments undoubtedly recognise the importance of helping people (especially older people) to stay healthy and active for as long as possible (i.e. maximise the number of healthy life years in the average lifespan), they should also recognise that success in increasing healthy or active life expectancy may not reduce the risk of the kind of final decline that most of us want to avoid. Most exponents of this view, moreover, think that we are fast approaching a point where a marginal increase in this risk would be unacceptable. In other words, they weigh the gain in healthy life years against the level of risk for the unwelcome outcome, and conclude that it is not (or will soon not be) worth having a marginal increase in healthy life years if they come at the cost of a significant increase in the risk.

The dismal view, as I have described it, clearly touches on questions of fact as well as questions of value. It is a question of fact, for example, whether or not increasing life expectancy at older ages does indeed increase the risk of experiencing a prolonged period of serious cognitive impairment before death (Matthews et al $2013^{2}$ ), and there is now a growing body evidence to suggest that life years with serious disability are not increasing (e.g. Andersen-Ranberg 2013; Sarkeala et al 2011). It is also a question of fact whether or not the more effective implementation of current strategies for maximising the number of healthy life years in the average lifespan will have the desired outcome for end-of-life trajectories. If it does, then we can achieve a 'win-win' outcome for more than a lucky or privileged sub-group within the population without resorting to massive spending on new biotechnologies based on improved understanding of biological ageing (Fries 2005, Olshansky et al 2006).

\footnotetext{
${ }^{2}$ This paper provides evidence of declining age-specific prevalence of dementia in the UK, and although this is not the same as a measure of individual lifetime risk, it is clearly relevant.
} 
The question of value - the normative problem - is different. It arises if emergent evidence on end-of-life trajectories can be construed in a way that requires us to reconsider our collective reckoning of the net benefits of longer lives. Firstly, we have to ask how we might incorporate the conclusion that the benefits to individuals are increasingly questionable into a collective reckoning, and secondly, we should ask, from the point of view of policy, whether it is necessary to engage with this normative problem in the first place. If it turns out that we can achieve a 'win-win' outcome, then the problem will simply not arise.

It is important here to unpack some of the assumptions of the dismal view. First, it is taken for granted not only that advanced old age can be associated with a very low quality of life, but also that there are circumstances in which external support and care, no matter how lovingly provided, cannot really touch the heart of the matter (e.g. the loss of sense of self and agency). Second, it is assumed that forward-looking individuals would be prepared to forego additional life years if they came at the cost of a substantial increase in the risk of ending life with a prolonged period of a certain kind of helplessness and dependency. Even if we allow for individual variations in judgment on this matter (e.g. how bad must this condition be for us to think it bad enough to be prepared to make this trade-off), there will be a tipping point for all of us. And finally, increasing longevity increases the risk - for all of us - that our quality of life will deteriorate to a condition beyond this point. What we are talking about here are of course the assessments that individuals make of the benefits to them of continuing longevity gains, but it is precisely the dominance of 'purely private' benefits in our collective reckoning of the gains from increased longevity that generates the normative problem. The argument is that our collective reckoning of the gains from increased longevity should reflect the pressures on individual assessments. 
How does this conclusion have practical significance for current policy? It has been argued that if life expectancy at older ages continues to increase at present rates, there is an increasing risk of outcomes (for individuals) that by general consensus are very undesirable view. But the rate of increase in longevity is at least partially in our control, and one way of exercising this control is to spend less on improving our capacity to delay death at older ages as well as more on improving our capacity to prevent agerelated degeneration. In other words, we should reallocate resources from one form of research investment to the other (Callahan 2003, Brown 2007).

This argument asserts that unless we subscribe to a kind of modified Friesian optimism, we are bound to consider possible trade-offs between two separable goals for health systems, mortality reduction and improvements in health-related quality of life. There is, however, an alternative. It is acknowledged that if we want a 'win-win' outcome, we have to adopt the compression of morbidity (or a reduction in the risk of prolonged frailty and cognitive impairment) as an explicit policy goal, and not measure success only by improvements in healthy or active life expectancy. A practical consequence of this view is that we should indeed increase our investment in research to develop new kinds of potentially high-cost interventions in the multiple and complex processes that lead to age-related degeneration (Academy of Medical Sciences 2009), but the proposal that we should spend less on improving our capacity to delay death at older ages is rejected. There are two reasons for this. In the first place, it is questionable whether the distinction between interventions that prolong life and interventions that improve its quality works in practice. Secondly, even if government does not have an explicit commitment to extending life expectancy at older ages, it is committed to reducing inequalities in late life mortality, and as I have suggested there are continuing pressures to strengthen this commitment. What is interesting about this rather pragmatic view is 
that the case for making the additional research investment in slowing down the ageing process must surely strengthen in line with judgments about the likelihood of being net losers unless we do so. It envisages a situation in which we would revise our collective reckoning of the benefits of continuing longevity gains to take account of the rising incidence of a negative outcome.

It is difficult therefore to sustain the idea that a trade-off between quantity and quality at life at older ages is essentially a matter for individual and private judgment. We may be very uncomfortable about the prospect of making a collective reckoning on this basis, but it looks as though we may not be able to avoid it. We have to be able to take a collective view on whether the bad outcome is bad enough to tip the balance, and on what would constitute an unacceptable increase in the risk of its occurrence. Ambivalence on this matter seems not to be an option.

\section{Conclusion}

In a discussion of the implications of the longevity transition for the application of values to public policy choices, we might expect some analysis of normative judgements about the provision of (and entitlement to) healthcare to older people. I have, however, deliberately ignored arguments about age-based rationing of clinical care, partly because this no longer seems to be a 'live' issue (if there is to be rationing, it will have to be framed in another, more socially acceptable, way), and partly because I wanted to shift attention to another question, namely, the implications of the transition for our collective reckoning of the benefits from continuing longevity increases.

It should be clear not only that what I have called the standard view is inapplicable in current conditions, but also that this conclusion requires us to revise many other 
elements in the normative framework that is used to shape policy-making on public health. We need to clarify the significance of social benefits - as distinct from individual benefits - for our reckoning of the gains from continuing longevity increases. We should acknowledge (and clarify) the implications of an understandable emphasis on the gains to individuals for the prioritization of policies on inequality in late-life outcomes. And finally, we have to decide whether or not to confront the dismal view not just on the grounds of its assumptions about matters of fact, but also because of its normative assumptions.

\section{References}

Academy of Medical Sciences (2009). Rejuvenating ageing research. London: UK Academy of Medical Sciences.

Andersen-Ranberg 2013. Trends over time in cognitive function and activities of daily living in Danish centenarians. Annual Review of Gerontology and Geriatrics, 33(1) 333-359.

Brown G. (2007). The living end: the new sciences of death, ageing and immortality. Palgrave Macmillan.

Callahan D (2003). What price better health? Hazards of the research imperative. Berkeley: University of California Press.

Canudas-Romo V. (2010). Three measures of longevity: time trends and record values. Demography, 47(2) 299-312.

Carnes BA, Olshansky SJ (2007). A realist view of aging, mortality and future longevity. Population and Development Review, 33(2) 367-381.

Daniels N (2008). Just health: meeting health needs fairly. Cambridge, Cambridge University Press. 
Eggleston KN, Fuchs VR. (2012). The new demographic transition: most gains in life expectancy now realised late in life. J Economic Perspectives, 26(3) 137-156.

Fleck LM (2010). Just caring: in defence of limited age-based rationing. Cambridge Quarterly of Healthcare Ethics, 19(1) 27-37.

Fries J. (2005). The compression of morbidity. Milbank Quarterly, 83(4) 801-823

Gruenwald D (2012). Can health care rationing ever be rational? Journal of Law, Medicine and Ethics, 40(1) 17-25

Horuichi S et al (2013). Modal age at death: lifespan indicator in an era of longevity extension. Vienna Yearbook of Population Research, vol. 11: 37-69

Howse K. (2014) Sustainability and intergenerational justice in age-related transfers. In: international handbook of aging and public policy. Edited by Harper $\mathrm{S}$ et al Elgar 2014

Mackenbach J (2012). The persistence of health inequalities in modern welfare states: the explanation of a paradox. Social Science and Medicine, 75(4) 761-769.

Marmot M (2010). Fair society, healthy lives (The Marmot Review). London, UCL Institute of Health Equity.

Matthews FE et al (2013). A two-decade comparison of prevalence of dementia in individuals aged 65 years and older from three geographical areas of England: results of the Cognitive Function and Ageing Study I and II. Lancet, 382: 1405-11.

Murphy KM, Topel RH (2006). The value of health and longevity. Journal of Political Economy, 114(5) 871-904.

Oliver D (2009). Age based rationing in health and social care services. British Medical Journal, 339:b3378

Olshansky SJ, Perry D, Miller RA, Butler RN (2006). In pursuit of the longevity dividend: what should we be doing to prepare for the unprecedented aging of humanity? The Scientist, 20 28-36

Overall, Christine (2003). Aging, death and longevity: a philosophical inquiry. Oakland, Cal. UC Press. 
Sarkeala T et al (2011). Disability trends among nonagenarians 2001-2007: the Vitality 90+ Study. European Journal of Ageing, 8 87-94.

Tepe M, Vanhuysse P. (2009). Are aging OECD welfare states on the path to gerontocracy? J Public Policy, 29(1) 1-28

Williams A (1997). Intergenerational equity: an exploration of the fair innings argument. Health Economics, 6(2) 117-132. 